\title{
Routine Is the Worst Enemy of the Dialysis Patient
}

\author{
Carlo Basile $^{a, b}$ Francesco Gaetano Casino ${ }^{a, c}$ \\ ${ }^{a}$ Clinical Research Branch, Division of Nephrology, Miulli General Hospital, Acquaviva delle Fonti, Italy; \\ ${ }^{\mathrm{b}}$ Associazione Nefrologica Gabriella Sebastio, Martina Franca, Italy; ' ${ }^{\mathrm{D}}$ Dialysis Centre SM2, Potenza, Italy
}

Dear Editor,

We read with great interest the review by Chazot and Jean [1] on incremental hemodialysis (HD). We fully agree that it requires a very high level of commitment from the nephrologist, the dialysis unit staff, and the patient. However, we strongly disagree when the authors state that "the safety and benefits of thrice-weekly HD therapy in incident patients outweigh the potential advantages of incremental dialysis" [1].

Actually, the majority of HD patients initiate dialysis with a relatively intense thrice-weekly HD (3HD/week) regimen of 3-4 h per session, with little individualization of prescription based on residual kidney function (RKF) or other patient factors [2]. Although the regulatory agencies might consider this HD regimen as "standard of care" and "adequate requirement," it is by no means perfect. The $3 \mathrm{HD} /$ week regimen has been assumed, until recently, almost as a dogma in the dialysis community [3]. Incredibly, the $3 \mathrm{HD} /$ wk schedule has been widely accepted worldwide without ever undergoing any randomized controlled trial (RCT) to examine whether less frequent HD treatments would be inadequate or harmful [4].

The optimal regimen for incident patients is not known. It is plausible that the routine practice of fixed-dose $3 \mathrm{HD} /$ week in incident patients with substantial RKF may be harmful, contributing to an accelerated loss of RKF $[5,6]$. Incremental HD is based on the simple idea of adjusting its dose according to the metrics of RKF. Indeed, most patients initiating dialysis have some degree of RKF, often residual renal urea clearance $(\mathrm{Kru})>3 \mathrm{~mL} / \mathrm{min}$ and urine output $>500 \mathrm{~mL} /$ day. Given the importance of RKF preservation in conservative therapy, it seems a contradiction to ignore the contribution of RKF in incident HD patients. What is important to note is that the challenge of preserving RKF or urine output in HD patients has never been taken seriously. The Kidney Disease Outcomes Quality Initiative suggests that minimum targets of adequacy of the dialysis dose $(\mathrm{Kt} / \mathrm{V})$ may be reduced in those with Kru $\geq 2 \mathrm{~mL} / \mathrm{min} / 1.73 \mathrm{~m}^{2}$ [7]. The European Best Practice Guidelines recommend measuring RKF in HD patients using the mean of urea and creatinine clearances and offer suggestions to incorporate this into the HD prescription to allow individual adjustments of dialysis prescription to meet minimum dialysis adequacy targets [8]. However, these guidelines do not recommend an incremental transition from less to more frequent HD over time, while, ironically, according to most peritoneal dialysis (PD) guidelines, $\mathrm{PD}$ dose should be adjusted up- ward parallel to decline in RKF, the preservation of which is a high priority target in $\operatorname{PD}[4,9]$.

Finally, we agree with the statement "routine is the worst enemy of the dialysis patient" made by Chazot and Jean [1]. This is the reason why the scientific nephrological community should strive to design and perform full-fledged RCTs testing incremental HD [10]. Such studies should be designed in order to include also the onceweekly HD treatment combined with lowprotein diet [11] and without low-protein diet [10] in the intervention arm of a potential RCT testing incremental HD. If the potential benefits of incremental HD will be confirmed, then starting dialysis at a full dose will be subjecting patients to unnecessarily long or more frequent treatments at higher cost.

\section{Disclosure Statement}

The authors have no conflicts of interest to declare.

\section{Funding Sources}

No funding sources were required for the preparation of the manuscript.

\section{KARGER}

(C) 2019 S. Karger AG, Basel
Carlo Basile, MD

Clinical Research Branch, Division of Nephrology

Miulli General Hospital

IT-70121 Acquaviva delle Fonti (Italy)

E-Mail basile.miulli@libero.it 


\section{References}

1 Chazot C, Jean G. End-stage kidney patients require hemodialysis therapy full start. Blood Purif. 2018 Dec;1-9.

2 Mathew AT, Fishbane S, Obi Y, Kalantar-Zadeh K. Preservation of residual kidney function in hemodialysis patients: reviving an old concept. Kidney Int. 2016 Aug;90(2):262-71.

3 Lowrie EG, Laird NM, Parker TF, Sargent JA. Effect of the hemodialysis prescription of patient morbidity: report from the National Cooperative Dialysis Study. N Engl J Med. 1981 Nov;305(20):1176-81.

4 NKF-K/DOQI clinical practice guidelines for hemodialysis adequacy: update 2000. Am J Kidney Dis. 2001 Jan;37(1 Suppl 1):S7-64.
5 Daugirdas JT, Greene T, Rocco MV, Kaysen GA, Depner TA, Levin NW, et al.; FHN Trial Group. Effect of frequent hemodialysis on residual kidney function. Kidney Int. 2013 May; 83(5):949-58

6 Golper TA, Mehrotra R. The intact nephron hypothesis in reverse: an argument to support incremental dialysis. Nephrol Dial Transplant. 2015 Oct;30(10):1602-4.

7 Hemodialysis Adequacy 2006 Work Group. Clinical practice guidelines for hemodialysis adequacy, update 2006. Am J Kidney Dis. 2006 Jul;48 Suppl 1:S2-90.

8 European Best Practice Guidelines. II.3 Haemodialysis dose and residual renal function
(Kr). Nephrol Dial Transplant. 2002;17(Suppl 7):S24.

9 Sandrini M, Vizzardi V, Valerio F, Ravera S, Manili L, Zubani R, et al. Incremental peritoneal dialysis: a 10 year single-centre experience. J Nephrol. 2016 Dec;29(6):871-9.

10 Casino FG, Basile C. How to set the stage for a full-fledged clinical trial testing 'incremental haemodialysis'. Nephrol Dial Transplant. 2018 Jul;33(7):1103-9.

11 Bolasco P, Cupisti A, Locatelli F, Caria S, Kalantar-Zadeh K. Dietary management of incremental transition to dialysis therapy: onceweekly hemodialysis combined with low-protein diet. J Ren Nutr. 2016 Nov;26(6):352-9. 